\title{
Diagnostic and prognostic gene expression signatures in 177 soft tissue sarcomas: hypoxia-induced transcription profile signifies metastatic potential
}

\author{
Princy Francis*1, Heidi Maria Namløs², Christoph Müller², Patrik Edén ${ }^{3}$, \\ Josefin Fernebro ${ }^{1}$, Jeanne-Marie Berner ${ }^{4}$, Bodil Bjerkehagen ${ }^{4}$, \\ Måns Åkerman ${ }^{5}$, Pär-Ola Bendahl11, Anna Isinger ${ }^{1}$, Anders Rydholm6, \\ Ola Myklebost ${ }^{2,7}$ and Mef Nilbert ${ }^{1}$
}

\begin{abstract}
Address: ${ }^{1}$ Department of Oncology, Institute of Clinical Sciences, Lund University, Lund, Sweden, ${ }^{2}$ Department of Tumor Biology, Rikshospitalet - Radiumhospitalet Health Centre, Oslo, Norway, ${ }^{3}$ Department of Theoretical Physics, Lund University, Lund, Sweden, ${ }^{4}$ Department of Pathology, Rikshospitalet - Radiumhospitalet Health Centre, Oslo, Norway, ${ }^{5}$ Department of Pathology, Institute of Clinical Sciences, Lund University, Lund, Sweden, ${ }^{6}$ Department of Orthopedics, Institute of Clinical Sciences, Lund University, Lund, Sweden and ${ }^{7}$ Department of Molecular Bioscience, University of Oslo, Norway

Email: Princy Francis* - princy.francis@med.lu.se; Heidi Maria Namløs - heidina@ulrik.uio.no;

Christoph Müller - christoph.muller@medisin.uio.no; Patrik Edén - patrik@thep.lu.se; Josefin Fernebro - josefin.fernebro@onk.lu.se; JeanneMarie Berner - j.m.c.berner@labmed.uio.no; Bodil Bjerkehagen - bodil.bjerkehagen@labmed.uio.no; Måns Åkerman - mans.akerman@skane.se; Pär-Ola Bendahl - par-ola.bendahl@med.lu.se; Anna Isinger - anna.isinger@onk.lu.se; Anders Rydholm - anders.rydholm@ort.lu.se; Ola Myklebost - ola.myklebost@biokjemi.uio.no; Mef Nilbert - mef.nilbert@onk.lu.se

* Corresponding author
\end{abstract}

Published: 14 March 2007

BMC Genomics 2007, 8:73 doi:10.1186/1471-2164-8-73

This article is available from: http://www.biomedcentral.com/I47I-2164/8/73

(C) 2007 Francis et al; licensee BioMed Central Ltd.

This is an Open Access article distributed under the terms of the Creative Commons Attribution License (http://creativecommons.org/licenses/by/2.0), which permits unrestricted use, distribution, and reproduction in any medium, provided the original work is properly cited.
Received: 14 December 2006 Accepted: 14 March 2007

which permits unrestricted use, distribution, and reproduction in any medium, provided the original work is properly cited.

\begin{abstract}
Background: Soft tissue sarcoma (STS) diagnosis is challenging because of a multitude of histopathological subtypes, different genetic characteristics, and frequent intratumoral pleomorphism. One-third of STS metastasize and current risk-stratification is suboptimal, therefore, novel diagnostic and prognostic markers would be clinically valuable. We assessed the diagnostic and prognostic value of array-based gene expression profiles using 27 k cDNA microarrays in 177, mainly high-grade, STS of I3 histopathological subtypes.

Results: Unsupervised analysis resulted in two major clusters - one mainly containing STS characterized by type-specific genetic alterations and the other with a predominance of genetically complex and pleomorphic STS. Synovial sarcomas, myxoid/roundcell liposarcomas, and gastrointestinal stromal tumors clustered tightly within the former cluster and discriminatory signatures for these were characterized by developmental genes from the EGFR, FGFR, Wnt, Notch, Hedgehog, RAR and KIT signaling pathways. The more pleomorphic STS subtypes, e.g. leiomyosarcoma, malignant fibrous histiocytoma/undifferentiated pleomorphic sarcoma and dedifferentiated/pleomorphic liposarcoma, were part of the latter cluster and were characterized by relatively heterogeneous profiles, although subclusters herein were identified. A prognostic signature partly characterized by hypoxia-related genes was identified among 89 genetically complex pleomorphic primary STS and could, in a multivariate analysis including established prognostic markers, independently predict the risk of metastasis with a hazard ratio of $2.2(P=0.04)$.

Conclusion: Diagnostic gene expression profiles linking signaling pathways to the different STS subtypes were demonstrated and a hypoxia-induced metastatic profile was identified in the pleomorphic, high-grade STS. These findings verify diagnostic utility and application of expression data for improved selection of high-risk STS patients.
\end{abstract}




\section{Background}

Soft tissue sarcomas (STS) account for 1\% of all malignancies and represent a heterogeneous group of mesenchymal tumors, the clinical management of which is challenging and requires multidisciplinary efforts that take the combined information from clinical investigations, imaging, histopathology, and cytogenetic and molecular genetic analyses into account. STS comprise more than 30 histological subtypes, although malignant fibrous histiocytoma (MFH)/undifferentiated pleomorphic sarcoma (UPS), liposarcoma, leiomyosarcoma, synovial sarcoma (SS), and malignant peripheral nerve sheath tumor (MPNST) account for three-fourth of the tumors [1]. Some STS subtypes are characterized by specific chromosomal translocations causing novel gene fusions e.g. SS18-SSX in SS and TLS-CHOP in myxoid/ round-cell liposarcoma. However, a large group of STS, e.g. MFH/UPS, leiomyosarcoma, and dedifferentiated/ pleomorphic liposarcoma, lack known specific recurrent alterations and are characterized by a multitude of rearrangements, amplifications, deletions, and somatic alterations, including mutations in TP53, deletions of RB1 and CDKN2A, and amplifications of MDM2 and CDK4 [2,3].

Gene expression studies have revealed diagnostic profiles and upregulation of specific pathways in sarcomas with type-specific genetic defects, e.g. SS, dermatofibrosarcoma protuberans, clear-cell sarcoma, Ewing sarcoma, rhabdomyosarcoma and gastrointestinal stromal tumors (GIST) [4-14] and have provided potential targets for novel therapies [15-18]. From a diagnostic point of view, the above mentioned tumor types can be identified from their underlying gene fusions, but the expression data reveal novel genes and pathways including multiple downstream targets of the resultant chimeric transcription factors, which provide a basis for the understanding of key biological changes in STS development. In contrast, molecular classification of the predominant, genetically complex STS subgroups, e.g. MFH/UPS, leiomyosarcoma, and dedifferentiated/pleomorphic liposarcoma, has been difficult with extensive pleomorphism that has precluded identification of recurrent profiles $[9,10,12,14,19,20]$. STS are highly malignant and metastases develop unpredictably in one-third of the cases, therefore, new prognostic markers would be of great clinical value. However, there have been only two reports of expression profiles associated with poor outcome in STS, both in leiomyosarcomas $[21,22]$. With the aim to establish diagnostic expression profiles for STS and to assess whether gene expression profiling can provide prognostic information, we used $27 \mathrm{k}$ cDNA microarrays to characterize the expression patterns in a mixed series of 177 STS, with particular focus on high-grade pleomorphic tumors.

\section{Results \\ Diagnostic Signatures Unsupervised analyses}

When the 177 STS were subjected to unsupervised cluster analysis, based on the 6140 spots that passed the filter criteria, the dendrogram split into two major branches (Figure 1). One branch (referred to as $S$ for simple/specific) consisted mainly of STS with simple, type-specific genetic defects and contained 31/32 SS, all 4 myxoid/round-cell liposarcomas, all 3 GIST and all 3 fibrosarcomas, in addition to 5/8 MPNST, 3/40 leiomyosarcomas, 5/60 MFH/ UPS, 2/4 STS not otherwise specified (NOS) and the single epithelioid sarcoma. Herein, SS, GIST, myxoid/roundcell liposarcomas, and MPNST formed tight subclusters. The other branch (referred to as $\mathrm{C}$ for complex) consisted mainly of genetically complex, often pleomorphic STS subtypes and contained 55/60 MFH/UPS, 37/40 leiomyosarcomas, all dedifferentiated/pleomorphic liposarcomas, myofibroblastic sarcomas, and extraskeletal osteosarcomas along with the remaining 3 MPNST, 2 STS NOS, 1 SS and the single giant-cell MFH and malignant mesenchymoma. A subset of 11 leiomyosarcomas formed a distinct tight subcluster within $\mathrm{C}$. When the 17 xenograft samples were included, a similar pattern of unsupervised clustering was observed and all 3 xenografts derived from tumors included in the study clustered next to their respective patient samples [see Additional file 1] suggesting that expression patterns of xenografts well reflect those of patient tumor material. A separate unsupervised cluster analysis of the 19 liposarcomas (16 tumors and 3 xenografts) separated the 5 myxoid/round-cell liposarcomas (characterized by the TLS-CHOP fusion) from the 14 dedifferentiated/pleomorphic liposarcomas (with complex genetic alterations) [see Additional file 2].

\section{Supervised analyses and discriminatory gene lists}

Discriminatory gene lists were generated by ranking genes based on their Golub-scores and performing 1000 random permutations to establish false-discovery rates (FDR) [see Additional files 3 and 4]. As expected, the strongest expression signals (with gene lists containing between 900 and 4000 genes with FDR of $11 \%$ ) characterized STS subtypes with specific genetic defects, e.g. SS, GIST and myxoid/round-cell liposarcoma. The MFH/UPS, leiomyosarcoma, and MPNST were characterized by discriminatory gene expression signals containing 90 - 300 genes with FDR of $11 \%$. Weak signals with high FDR characterized the fibrosarcoma (50\% FDR for top 200) and dedifferentiated/pleomorphic liposarcoma (66\% FDR for top $150)$, whereas myofibroblastic sarcoma and extraskeletal osteosarcoma were small heterogeneous groups without discriminatory profiles. 


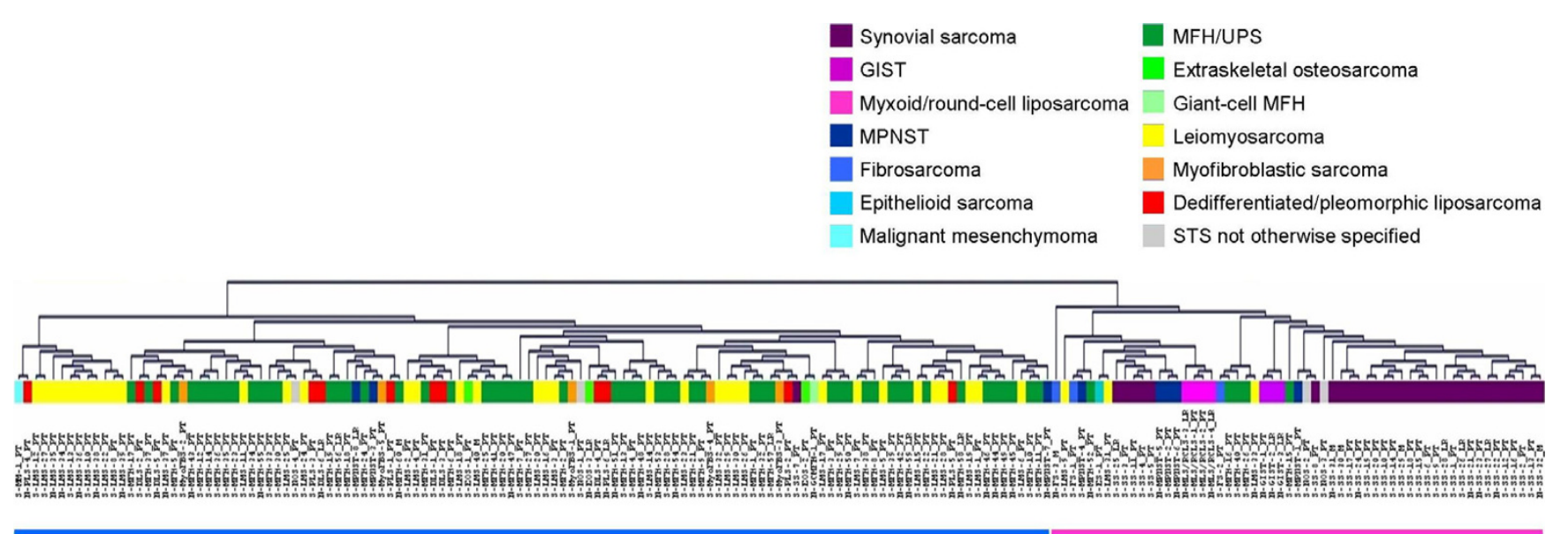

Subcluster C

Subcluster S

Figure I

Unsupervised cluster analysis of the I77 STS samples resulted in two major subclusters: C dominated by pleomorphic STS subtypes with complex genetic alterations and $\mathbf{S}$ mainly containing STS of distinct histopathological subtypes with specific fusion genes or mutations.

\section{Synovial Sarcoma}

The SS were characterized by the strongest expression signature containing 4000 differentially expressed genes with a FDR of only $11 \%$. Multiple developmental pathways that interact to regulate embryonic development and organogenesis were upregulated in SS. These genes included ERBB2, FGFR1, FGFR3, FGF18, and FRAG1 from the EGF and FGF receptor signaling pathways, members of the Hedgehog $(\mathrm{Hh})$ signaling pathway like $P T C H$, $S M O, B M P 7, F O X M 1$ and CSNK1E, retinoic acid receptor (RAR) pathway genes like RARA, RARG, MDK, MEIS1 and $P R A M E$, and genes involved in Notch receptor signaling like NOTCH1, JAG1 and the transducin-like enhancer of split genes. EASE (Expression Analysis Systematic Explorer) identified overexpression of the Wnt receptor signaling pathway including AXIN2, LEF1, TCF7, WISP2 and the frizzled homologs, and the TGF- $\beta$ signaling pathway including RUNX3, SMAD6, TGFB1, TGFB2 and the bone morphogenetic proteins. One of the largest functional groups of upregulated genes was that involved in chromatin remodeling including several histones and SWI/SNF related matrix associated actin dependent regulator of chromatin (SMARC) genes. A large number of neural differentiation genes like EFNA1, NCAM1, NEDD5, NPDC1 and OLFM1, ribosomal protein genes, many forkhead box transcription factors and the SS chromosome X breakpoint genes SSX1 and SSX3 were also highly expressed [see Additional files 5 and 6].

\section{Gastrointestinal stromal tumor}

The GIST, with activating mutations in the KIT gene were characterized by a distinct expression profile of 900 genes (11\% FDR), including top overexpressed genes involved in the KIT receptor signaling pathway, e.g. KIT, and PRKCQ (SCF, PIK3CB and PIK3R1 were also overexpressed but a bit further down the list beyond the $11 \%$ FDR cut-off), and other developmental pathways, e.g. BMP4, FGF2, IGF2, SFRP1 and TLE4, as well as neurogenesis and neural differentiation genes like SMPD1, HOXA4, CIT, HOXA9, SIM2, NPTX1, NEDD5 and DCTN1. Other groups of highly expressed genes identified in the EASE analysis were those involved in protein transport, lipid metabolism and kinase activity [see Additional files 7 and $8]$.

\section{Myxoid/round-cell liposarcoma}

A distinct expression signature of about 1000 differentially expressed genes ( $11 \%$ FDR) characterized the myxoid/round-cell liposarcomas. Herein, several lipid metabolism genes, including DGKD, EBPL, FABP5, LPL, MGLL and PPARG were upregulated, as were many developmental genes, ribosomal subunit genes and genes involved in amino acid and carboxylic acid metabolism [see Additional files 9 and 10].

\section{Malignant peripheral nerve sheath tumor}

Golub-score analysis identified a 100-gene signature (11\% FDR) characterized by overexpression of developmental pathway genes like FRAG1, WISP2, RARRES3, SPRY1 and SMO from, e.g. the Wnt, RAR and Hh signaling pathways. Moreover, genes related to neural development such as NEDD4, NPDC1, GSTP1, and DSCR1, and several ribosomal protein genes were also highly expressed [see Additional files 11 and 12]. 


\section{Leiomyosarcoma}

A 200-gene signature (11\% FDR) characterized by overexpression of muscle-specific genes like ACTN3, CALD1, MBNL1, MLC1, MYH11, MYL4, SLMAP, TPM2 and TAGLN3 was identified in the leiomyosarcomas. EASE analysis also identified upregulation of carbohydrate metabolism and energy pathway genes [see Additional files 13 and 14].

\section{Malignant fibrous histiocytoma/undifferentiated pleomorphic sarcoma}

A 300-gene signature (11\% FDR) was identified for the MFH/UPS samples and the top upregulated functional groups included cathepsins and genes related to protein degradation, inflammatory response, cell motility, proliferation, cell-cycle control, and intracellular signaling [see Additional files 15 and 16].

\section{Discriminatory gene lists with high FDR}

The gene lists for dedifferentiated/pleomorphic liposarcoma and fibrosarcoma had large numbers of false positives among the ranked genes. However, the dedifferentiated/pleomorphic liposarcomas were characterized by a weak discriminatory 150-gene signature, which when used in a supervised cluster analysis grouped 5/12 dedifferentiated/pleomorphic liposarcomas tightly with $2 \mathrm{MFH} / \mathrm{UPS}, 2$ leiomyosarcomas and 1 fibrosarcoma. Despite the high FDR, CDK4, MDM1, MDM2, OS4 and $S A S$, were among the top overexpressed and are along with several other highly expressed genes, e.g. NUP107, SLC26A10, SLC35E3, TMBIM4, TSFM and YEATS4, located in the 12q14 and 12q15 amplicons. EASE analysis also identified the above-mentioned gene group on chromosome 12q14-q15. Interestingly, also the MFH/UPS, the leiomyosarcomas and the fibrosarcoma that clustered tightly with the dedifferentiated/pleomorphic liposarcomas showed amplification of CDK4 and MDM2 when analyzed by array comparative genomic hybridization (data not shown) or Southern blot analysis [23]. In addition, genes involved in receptor activity, signaling and lipid metabolism (some of which have previously been reported in liposarcoma) such as ACAA2, ARSA, DHRS3, PDE3A, and PPARA, were upregulated [see Additional files 17 and 18].

Golub-score analysis identified a relatively poor discriminatory signal of 200 genes for the fibrosarcomas, which regardless of high FDR contained several of the upregulated genes previously associated with fibrosarcoma, e.g. BMI1, H1F0, LEF1, RBM4, ITM2A, IGFBP2 and PTGS2 [10]. Upregulation of developmental genes like $B M P 7$, SMO, VANGL2, SFRP1, PRRX1, MDK, OLFM, IGFBP3, IGFBP5 and TGFBR3 in the fibrosarcoma samples suggests similarity to SS, GIST, myxoid/round-cell liposarcoma and MPNST explaining its classification within subcluster
$S$ in Figure 1 [see Additional files 19 and 20]. This shows that FDR, though important, cannot be taken at face value without the risk of losing biologically relevant information, especially in the case of STS where high FDR may result not only from heterogeneity and errors in diagnosis but also due to common pathogenic pathways resulting in similarities or overlap of expression profiles between different STS subtypes.

\section{Myxoid/round-cell liposarcoma vs. Dedifferentiated/pleomorphic liposarcoma}

In an independent analysis (including 16 tumor and 3 xenograft samples), the 5 myxoid/round-cell liposarcomas were compared to the 14 dedifferentiated/pleomorphic liposarcomas. A 800 -gene signature (11\% FDR) distinguished the two groups [see Additional file 2]. Developmental genes including members of the Wnt receptor signaling pathway, e.g. DAAM1, FZD8, MYC, PRICKLE1, SFRP1 and WISP2, and neurogenesis genes, e.g. CPNE6, EFNA5, FEZ2, LHX2, MDK and NTNG1 were upregulated in the myxoid/round-cell liposarcomas as compared to the dedifferentiated/pleomorphic liposarcomas, as were several ribosomal protein genes and genes involved in adhesion and amino acid metabolism. Genes highly expressed in the dedifferentiated/pleomorphic liposarcomas included cell-cycle genes like CCNA2, CCNB2, CDC2, KIFC1, KIF23 and PTTG1, motility genes like AMFR, ANXA1, CKB, CNN2 and FN1 and homeostasis-related genes. A smaller number of lipid metabolism genes were overexpressed in the myxoid/round-cell liposarcomas compared to the dedifferentiated/pleomorphic liposarcomas with genes such as DGKD, EBPL, FABP5, FDFT1, LPL and PPARG upregulated in the former group, while ADM, ANXA1, ANXA4, CRYL1, GRN, PLA2G4A, PLA2G12A, PLD1 and PLTP were overexpressed in the latter [see Additional files 2 and 21]. Similar results were obtained even with the exclusion of the 3 xenograft samples further supporting the notion that xenografts reflect gene expression patterns of patient tumor material and can with some caution be included in gene expression studies of STS to increase sample size for rare tumor types.

\section{Prognostic Signature}

About $50 \%$ of the patients diagnosed with STS succumb to their disease owing partly to the high metastatic potential of these tumors but risk-assessment is rather difficult with very few reliable prognostic factors [24]. The different STS subtypes are associated with variable outcome with a favorable prognosis for patients with myxoid liposarcomas and a high risk of metastases for patients with MFH/UPS and SS [25]. Since the majority (76\%) of the tumors in our series were high-grade, pleomorphic STS, we chose to evaluate the presence of a prognostic signature within subcluster $\mathrm{C}$ among the most heterogeneous samples. After excluding local recurrences, metastases, 
samples treated with preoperative chemotherapy, the single SS and 3 MPNST (that were outliers from cluster S), the 11 leiomyosarcomas with a distinct profile, and the dedifferentiated/pleomorphic liposarcomas with the MDM2CDK4 double amplification, 89 primary STS remained for the analysis. Exclusion of the leiomyosarcomas and liposarcomas that formed subclusters within $\mathrm{C}$ was done in order to detect the more subtle prognostic signal among the most pleomorphic samples (Table 1).

\section{Supervised analysis}

Golub-score analysis with 1000 random permutations identified a 200-gene prognostic signature (35\% FDR) distinguishing tumors that metastasized $(n=39)$ from those that remained metastasis-free $(n=50)$ (Figure 2). In order to obtain a more robust list of discriminators, a consensus gene list of 244 genes with median rank less than 700 was generated, as described in the methods section, with the majority of the genes from the Golub-score ranked list being present in the consensus list. Hierarchical clustering based on the consensus list split the 89 samples into two clusters with metastases developing in $6 / 36$ $(16 \%)$ in the low-risk cluster compared to $33 / 53$ (62\%) in the high-risk cluster (Figure 3 ). The genes overexpressed in the metastasizing tumors included HYOU1, HIF1A, HIG2, DDIT4, TFRC, ERO1L, PLOD2, and ADM suggesting an expression program triggered by hypoxia. Hypoxia causes stabilization of the HIF-1 transcription factor that mediates the induction of several genes including those promoting anaerobic glycolysis [26] and the most significant functional group identified in the EASE analysis included glycolytic enzymes and glucose transporters like ENO1, ENO2, PYGL, FUT1, HK2, GLUT1, GYS1, PDK1, CA2, $C A 12, P G K 1$ and $L D H B$, many of which are known markers for hypoxia. The overexpression of hypoxia-induced genes in metastasizing primary tumors provides a basis for further studies of hypoxia in STS to clarify its role in metastasis and to verify potential prognostic and therapeutic utility. In addition, several genes involved in cell proliferation, adhesion and motility e.g. SYMPK, ACTN1, $B Y S L, V C L, N R C A M, Y A R S$ and TLN1 were among the discriminators [see Additional file 22].

\section{Support vector machine (SVM) leave-one-out cross-validation and statistical analyses}

Development of metastasis correlated with tumor size $(P$ $=0.006$, Mann-Whitney's U and Kruskal-Wallis tests) and necrosis $\left(P=0.013\right.$, Pearson $\chi^{2}$ test $)$, but not with vascular invasion $\left(P=0.166\right.$, Pearson $\chi^{2}$ test $)$. The SVM leave-oneout cross-validation correctly classified $64 \%$ of the samples (area under receiver operating characteristic (ROC) curve $=0.64, P=0.007$ ) into two groups with metastasis developing in 58\% (25/43) of the patients in the high-risk group, compared to $30 \%(14 / 46)$ in the low-risk group $(P$ $=0.008$, Pearson $\chi^{2}$ test) and significantly predicted metastasis-free survival $(P=0.01$, logrank test, Figure 4$)$. The corresponding hazard ratio (HR) from a univariate Cox-regression analysis was $2.4(P=0.01)$ and in a multivariate analysis including the established prognostic factors size, necrosis and vascular invasion, the profile predicted outcome with a HR of $2.2(P=0.04)$ (Table 2$)$.

\section{Discussion}

From a clinical diagnostic perspective, most STS with specific fusion proteins can be correctly classified based on the combined data from histopathology, immunostainings, and cytogenetic and/or molecular genetic analyses. This stands in contrast to the genetically complex STS subtypes, the diagnosis of which is hampered by suboptimal reproducibility due to extensive histopathological heterogeneity, pleomorphism and lack of type-specific genetic defects. Distinct and homogenous expression profiles have been reported in SS, dermatofibrosarcoma protuberans, clear-cell sarcoma, myxoid/round-cell liposarcoma and GIST [4-13]. Furthermore, the discriminatory profiles that often contain genes located downstream of the typespecific pathogenic gene fusions or mutations have provided novel targets for molecular therapy [15-18]. Gene expression profiles have provided clues to the histogenesis of some STS subtypes, suggested similarities between others and allowed distinction between pathologically inseparable lesions, e.g. neural crest origin of SS, close relation between clear-cell sarcoma and melanoma, and distinct expression profiles for well-differentiated and dedifferentiated liposarcomas $[9,11,27]$. Current data from the more pleomorphic STS, however, indicate that their expression profiles are indeed heterogeneous and in these tumor types the primary goal may rather be to identify novel, yet unidentified subgroups, and to clarify deregulated genes and pathways.

Unsupervised cluster analysis of the 177 STS identified two major subclusters; S containing STS with specific fusion genes or mutations, e.g. SS, myxoid/round-cell liposarcoma and GIST, and subcluster $\mathrm{C}$ with genetically complex, often pleomorphic STS subtypes, e.g. MFH/UPS, leiomyosarcoma and dedifferentiated/pleomorphic liposarcoma (Figure 1). This is in line with results from previous gene expression and proteomic profiling studies $[10,19,28]$.

Discrimination scoring identified genes and pathways differentially regulated in the STS subtypes, with considerable amount of overlap with previously published gene lists despite the differences in tumor material and array platforms $[4,5,7,9,10,12,19,20]$. Expression profiles in the distinct subtypes were strong with low FDR whereas the pleomorphic ones had relatively heterogeneous profiles with higher FDR. Identification of diagnostic markers that clearly distinguish different subtypes requires gene 
Table I: Summary of the clinicopathological data of the 177 and 89 STS samples

\begin{tabular}{|c|c|c|}
\hline Factor & Diagnostic signature $n=\mid 77$ & Prognostic signature $n=89$ \\
\hline Sex (male/female) & $88 / 89$ & $50 / 39$ \\
\hline Age, median (range) years & $66(11-94)$ & $69(33-93)$ \\
\hline \multicolumn{3}{|l|}{ Histological subtypes } \\
\hline Malignant fibrous histiocytoma (MFH) & $61^{0}$ & 54 \\
\hline Leiomyosarcoma & 40 & 27 \\
\hline Synovial sarcoma & 32 & 0 \\
\hline Liposarcoma & $16 *$ & 0 \\
\hline Malignant peripheral nerve sheath tumor & 8 & 0 \\
\hline Myofibroblastic sarcoma & 5 & 5 \\
\hline STS not otherwise specified & 4 & 2 \\
\hline Extraskeletal osteosarcoma & 3 & I \\
\hline Fibrosarcoma & 3 & 0 \\
\hline Gastrointestinal stromal tumors & 3 & 0 \\
\hline Epithelioid sarcoma & 1 & 0 \\
\hline Malignant mesenchymoma & 1 & 0 \\
\hline \multicolumn{3}{|l|}{ Grade } \\
\hline II & 6 & I \\
\hline III & 32 & 12 \\
\hline IV & 139 & 76 \\
\hline \multicolumn{3}{|l|}{ Tumor size } \\
\hline Median (range) cm & $8(1-40)$ & $9(2-30)$ \\
\hline$<5 \mathrm{~cm}$ & $4 I$ & 19 \\
\hline $5-10 \mathrm{~cm}$ & 74 & 38 \\
\hline$>10 \mathrm{~cm}$ & 62 & 32 \\
\hline \multicolumn{3}{|l|}{ Tumor location } \\
\hline Extremity & 144 & 78 \\
\hline Trunk wall & 19 & 7 \\
\hline Retroperitoneum & 7 & 3 \\
\hline Other & 7\# & I \\
\hline \multicolumn{3}{|l|}{ Tumor depth } \\
\hline Superficial & 37 & 22 \\
\hline Deep & 118 & 63 \\
\hline Unclassified & 22 & 4 \\
\hline \multicolumn{3}{|l|}{ Necrosis } \\
\hline Absent & 48 & 23 \\
\hline Present & 106 & 66 \\
\hline Unclassified & 23 & 0 \\
\hline \multicolumn{3}{|l|}{ Vascular invasion } \\
\hline Absent & 121 & 72 \\
\hline Present & 31 & 17 \\
\hline Unclassified & 25 & 0 \\
\hline \multicolumn{3}{|l|}{ Treatment } \\
\hline Surgery alone & 107 & 58 \\
\hline Postoperative radiotherapy & 51 & 22 \\
\hline Postoperative chemotherapy & 3 & 2 \\
\hline Postoperative radio- and chemotherapy & 10 & 7 \\
\hline Preoperative radio- or chemotherapy & 6 & 0 \\
\hline \multicolumn{3}{|l|}{ Surgery } \\
\hline Wide & 90 & 57 \\
\hline Marginal & 66 & 28 \\
\hline Intralesional & 15 & 4 \\
\hline Unclassified & 6 & 0 \\
\hline
\end{tabular}

Includes 47 storiform, 13 myxoid, and I giant-cell MFH

* Includes 4 myxoid/round cell liposarcomas, 6 dedifferentiated liposarcomas, and 6 pleomorphic liposarcomas

\# Includes localizations in the abdomen, the mediastinum, and the head and neck 


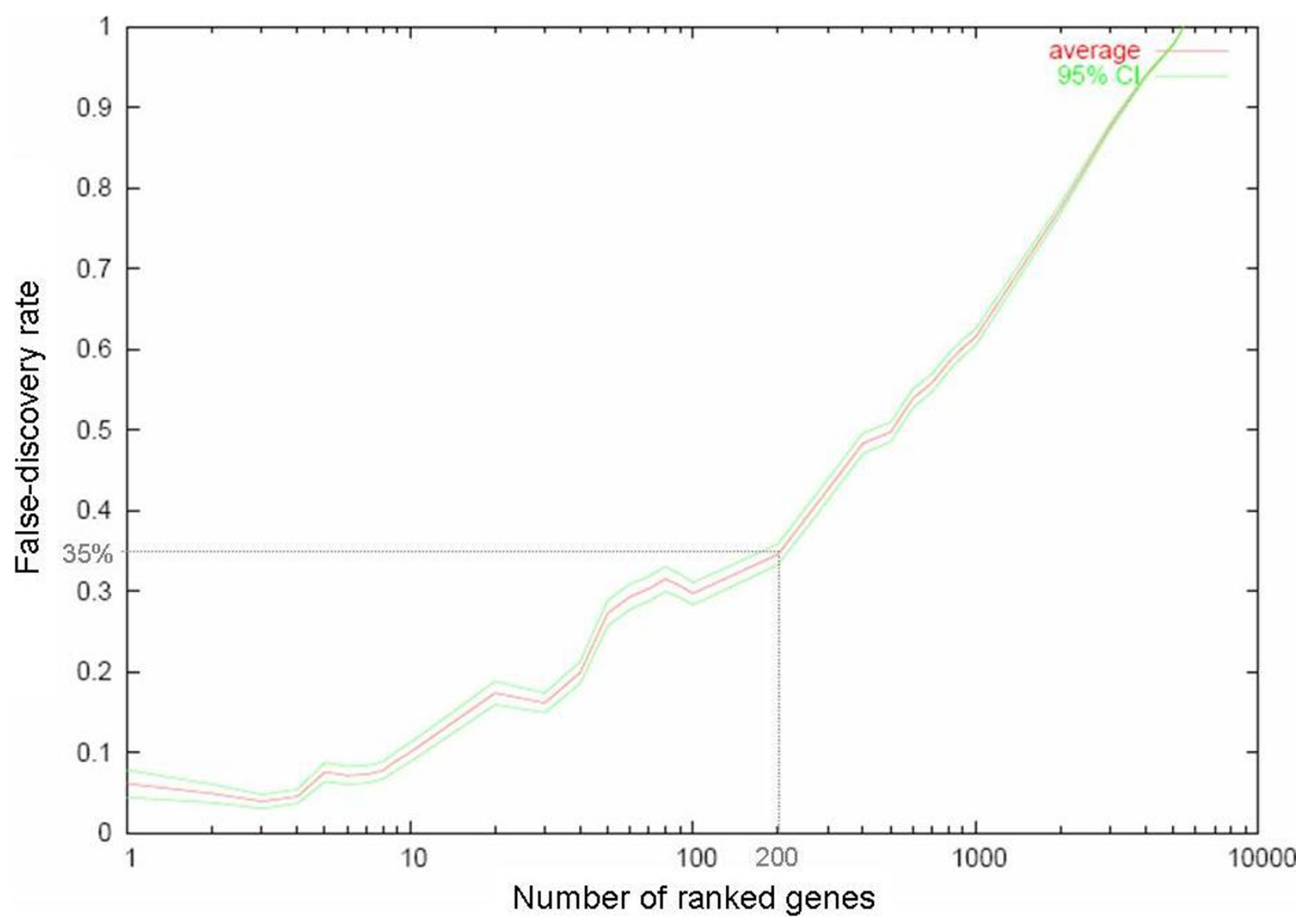

Figure 2

Plot showing FDR within the Golub-score ranked prognostic genes distinguishing the primary tumors that developed metastasis from those that remained metastasis-free. The number of ranked genes is plotted along the $x$-axis and FDR along the $y$-axis.

lists with very low FDR, but inherent heterogeneity, lack of clear-cut boundaries between subtypes, misdiagnoses and common pathogenic genes and pathways make it rather difficult to generate such strong diagnosis-specific expression profiles in the pleomorphic STS. Some studies chose to exclude samples that did not cluster according to histopathological diagnosis thereby reducing FDR by increasing homogeneity within the subgroups $[7,10]$. In the current study, outliers were included but lenient cutoffs were employed allowing some amount of false positives in the gene lists, which were then analyzed using EASE to identify functionally correlated genes. The risk of signifying false positives was reduced by focusing on upregulated pathways and functional groups rather than on individual genes. This approach helped identify biologically relevant genes in dedifferentiated/pleomorphic liposarcoma and fibrosarcoma despite high FDR and upregulation of similar functional groups in SS, GIST, myxoid/round-cell liposarcoma, MPNST and fibrosarcoma.

Although alternative SSX fusions and various lines of differentiation can be demonstrated in SS [29,30], they display homogenous and distinct expression profiles that enable clear distinction from other STS subtypes $[4,9,10,12,19,20]$ and our finding of 4000 differentially expressed genes is in line with these results. In the unsupervised clustering, all but one SS were part of subcluster S, within which 5 formed a tight subcluster, together with 3 MPNST samples on a separate branch, away from the main SS subcluster (Figure 1). Supervised clustering based on the 4000 genes also showed close clustering of SS to MPNST [see Additional file 5]. Previous studies have shown that SS and MPNST share similar patterns of gene expression with upregulation of neuroectodermal differentiation genes thereby suggesting a neural crest origin $[4,7,9]$ and several neural differentiation genes were also 


\begin{tabular}{lcll}
-1.0 & 0.0 & High-risk Cluster & 1.0 \\
\hline
\end{tabular}
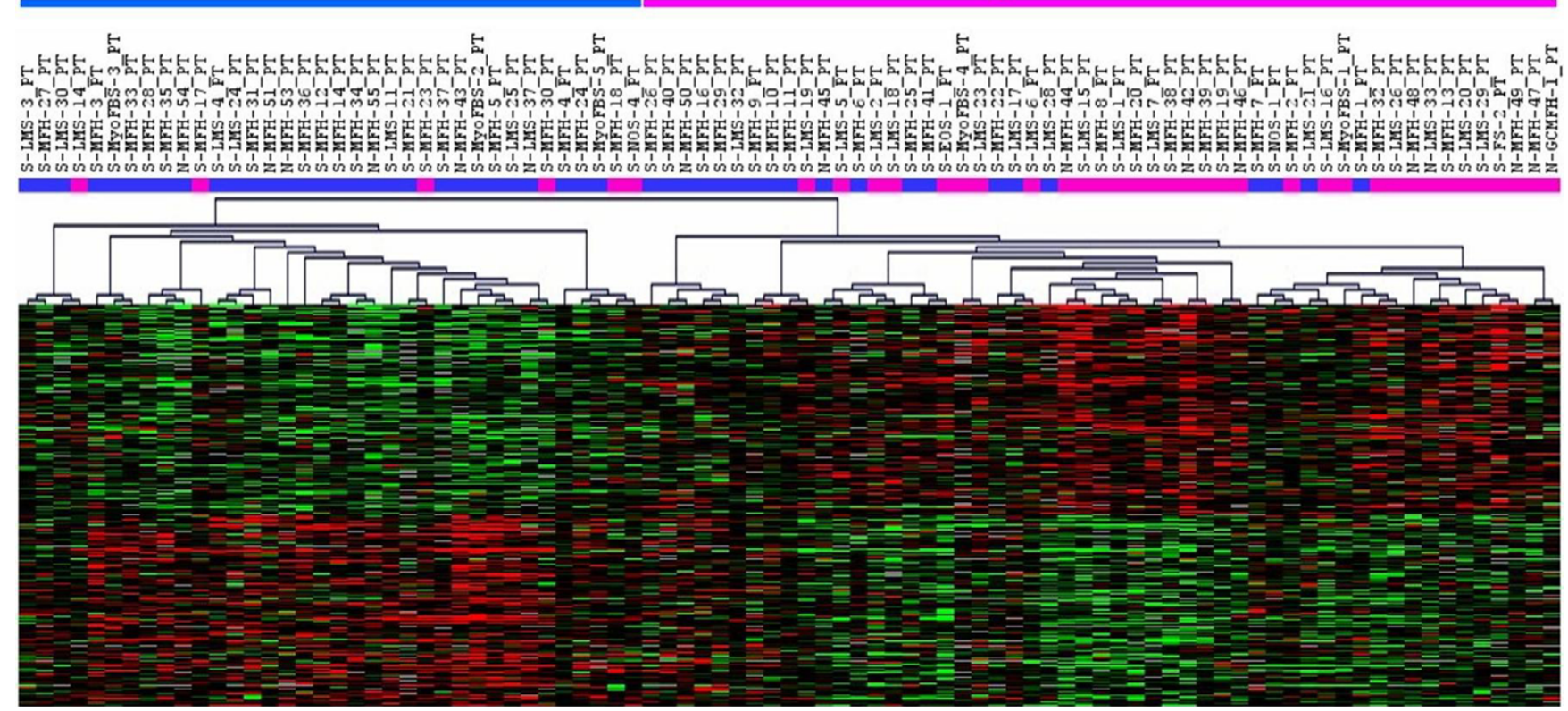

Figure 3

Supervised clustering of the 89 primary pleomorphic STS samples based on the 244-gene prognostic signature.

upregulated in the present study. The SS18-SSX fusion product controls gene expression by association with chromatin remodeling complexes through interactions with SWI/SNF complexes and histones [31-33]. Interestingly, chromatin-remodeling genes including several his- tones and SMARC genes constituted one of the largest functional groups upregulated in the SS. Moreover, the genes identified herein verified the significance of developmental pathways including the FGF, EGF, TGF- $\beta$, Wnt, Notch, retinoic acid and Hh receptor signaling pathways,

Table 2: Univariate and multivariate analysis in the prognostic subset of 89 primary tumors

Metastasis-free survival

\begin{tabular}{|c|c|c|c|c|c|c|}
\hline & \multirow{3}{*}{ Total Number } & \multirow{3}{*}{ Metastasis-free/Metastasis developed } & \multirow{2}{*}{\multicolumn{2}{|c|}{ Univariate analysis }} & & \\
\hline \multirow[t]{2}{*}{ Factors } & & & & & \multicolumn{2}{|c|}{ Multivariate analysis } \\
\hline & & & HR $(95 \% \mathrm{Cl})$ & $P$-value & HR $(95 \% \mathrm{Cl})$ & $P$-value \\
\hline Number of samples & 89 & $50 / 39$ & & & & \\
\hline \multicolumn{7}{|l|}{ Tumor size } \\
\hline Median (range) $\mathrm{cm}$ & $9(2-30)$ & $7.5(2-28) / 10(3-30)$ & $1.1(1.02-1.12)$ & 0.012 & $1.2(1.01-1.14)$ & 0.021 \\
\hline \multicolumn{7}{|l|}{ Necrosis } \\
\hline Absent & 23 & $18 / 5$ & 1.0 & & & \\
\hline Present & 66 & $32 / 34$ & $2.9(1.12-7.50)$ & 0.028 & $1.6(0.55-4.52)$ & 0.402 \\
\hline \multicolumn{7}{|l|}{ Vascular invasion ${ }^{a}$} \\
\hline Absent & 72 & $43 / 29$ & 1.0 & & & \\
\hline Present & 17 & $7 / 10$ & $2.4(1.11-5.17)$ & 0.026 & $2.2(0.98-5.00)$ & 0.055 \\
\hline \multicolumn{7}{|c|}{ Cross-validated classifier ${ }^{a}$} \\
\hline low-risk group & 46 & $32 / 14$ & 1.0 & & & \\
\hline high-risk group & 43 & $18 / 25$ & $2.4(1.20-4.73)$ & 0.013 & $2.2(1.04-4.62)$ & 0.04 \\
\hline
\end{tabular}

aProportional hazards assumptions assume constant mortailty ratios and are therefore not met. Thus, the estimated HRs should be interpreted as averages over time. The effects are considerably larger initially and level off with time. 


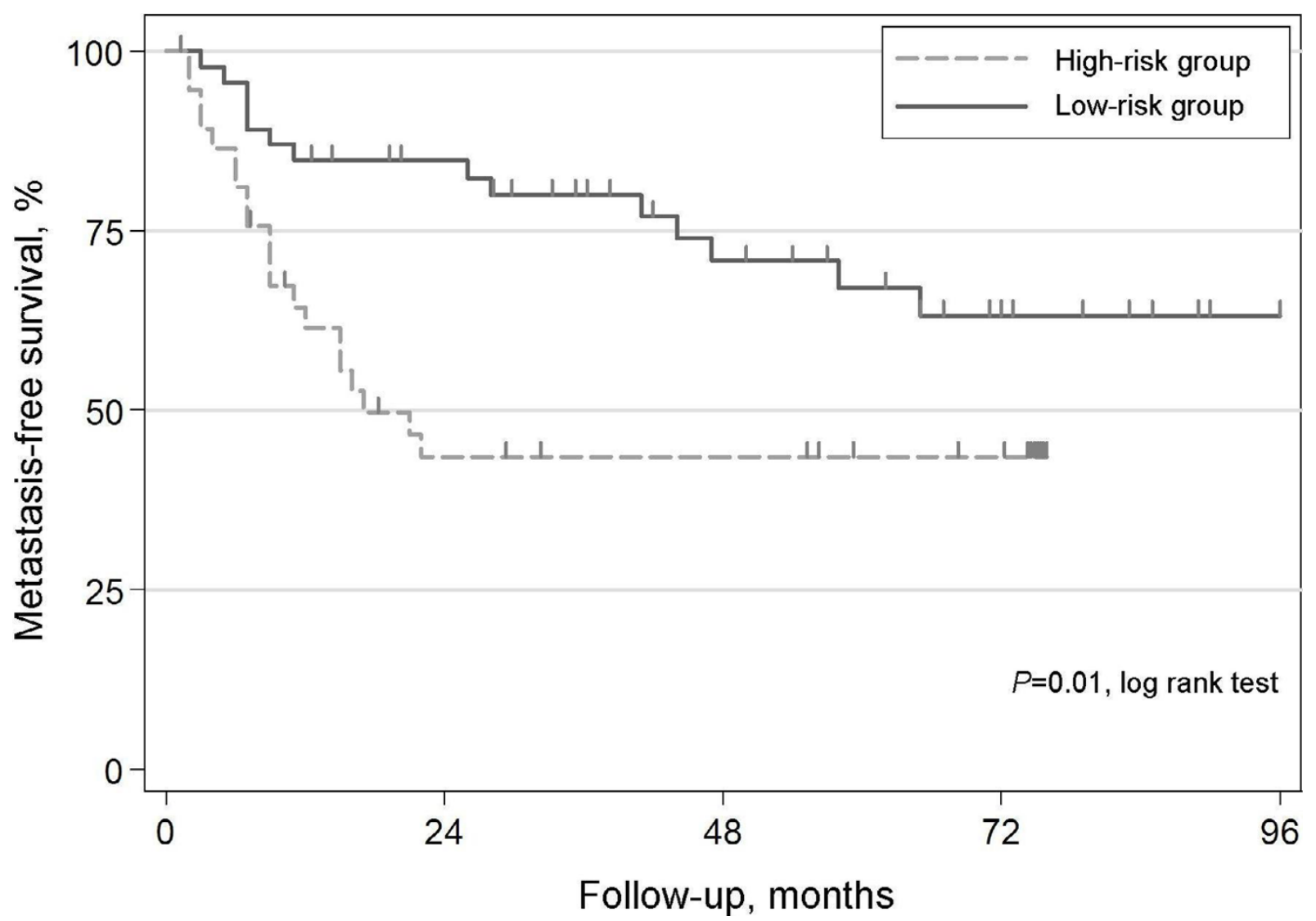

Figure 4

Kaplan-Meier estimates of metastasis-free-survival for patients included in the prognostic subset (5 cases with metastasis at diagnosis were excluded) classified as high-risk or low-risk by the SVM cross-validated classifier.

the targeted inhibition of which may provide novel therapeutic options.

MPNST may morphologically mimic SS [34] and in the unsupervised analysis, 5/8 MPNST clustered within subcluster S, and 3 with a subset of SS. Several developmental, neural differentiation and ribosomal protein genes were found to be overexpressed in both MPNST and SS. Fibrosarcomas, like the MPNST, have been shown to cluster with the SS $[7,10]$. The fibrosarcomas in this study were part of subcluster $S$ and a weak expression signature including many developmental genes distinguished these tumors from the remaining STS.

GIST constitute a distinct STS subtype, $80 \%$ of which carry KIT gene activating mutations [35]. These tumors demonstrate distinct expression profiles [5], with upregulation of genes within the KIT signaling pathway. In addition, several genes involved in neurogenesis and neural differentiation were overexpressed, as were muscle-specific genes like smoothelin and myosin, which may reflect the suggested origin of GIST from the interstitial pacemaker cells of Cajal [36].

Liposarcomas account for about $20 \%$ of STS and within this subtype, the myxoid/round-cell liposarcomas characterized by the TLS-CHOP or EWS-CHOP fusions [37] formed a distinct cluster closely related to a subset of SS and MPNST within subcluster $S$ with upregulation of several developmental and ribosomal protein genes (Figure 1 ). One of the top most upregulated genes was the lipid metabolism gene PPARG that regulates adipocyte differentiation and constitutes a potential therapeutic target $[38,39]$. The dedifferentiated/pleomorphic liposarcomas contain complex genetic alterations and were scattered among the pleomorphic samples in the unsupervised clustering. Most dedifferentiated liposarcomas are characterized by amplifications of MDM2 and CDK4 as part of the $12 \mathrm{q}$ amplicons involved in the formation of ring-chromosomes $[40,41]$. A relatively weak discriminatory signature mainly characterized by overexpression of the $12 \mathrm{q}$ amplicon genes distinguished a small subset of the dedif- 
ferentiated/pleomorphic liposarcomas [see Additional file 17]. PPARA and other lipid metabolism genes were also overexpressed. Comparison between myxoid/roundcell and pleomorphic/dedifferentiated liposarcomas revealed overexpression of ribosomal proteins and developmental genes related to Wnt signaling and neurogenesis in the former group, whereas genes related to cell-cycle, homeostasis, and a greater number of lipid metabolism genes were upregulated in the latter. Skubitz et al. demonstrated separation of myxoid liposarcoma from nonmyxoid liposarcoma using a set of ribosomal genes [42].

Our series included a large proportion of pleomorphic, undifferentiated STS with the hope of gaining novel insights into the origin of these genetically complex tumors and establishing a more refined classification. About one-third of the leiomyosarcomas clustered tightly within subcluster $C$ and a 200-gene signature with overexpression of genes related to muscle structure and function was identified in these tumors (Figure 1). This is in line with previous results from gene expression and proteomic profiling demonstrating that while the more pleomorphic leiomyosarcomas cluster with the MFH, another more distinct subset cluster separately $[19,28]$. MFH was introduced as a separate diagnostic entity in the 1960s, but constitutes a heterogeneous group of poorly differentiated tumors with poor diagnostic reproducibility [1]. In our series, one-third of the tumors represented MFH/UPS, all but 5 of which fell within subcluster C (Figure 1). A 500gene signature grouped together about half of the MFH/ UPS [see Additional file 15] including several genes from the extracellular matrix and inflammatory response, reflecting the fibrous and histiocytic features of these tumors, as well as others involved in the regulation of cellcycle, proliferation, adhesion, motility and protein degradation.

Novel prognostic and therapeutic markers would be of great clinical value in STS since risk stratification is currently difficult and adjuvant treatments are toxic and hampered by low efficacy. We identified a 244-gene prognostic signature in 89 primary, high-grade STS mainly representing MFH/UPS and leiomyosarcoma. This signature was characterized by upregulation of several hypoxiarelated genes (e.g. HIF1A and its targets) and genes involved in cell proliferation, adhesion and motility in metastasizing STS. Our data are the first to suggest a prognostic profile modulated at least in part by hypoxia in a large series of highly malignant STS of mixed types. The cross-validated classifier predicted metastasis with an accuracy of $64 \%$ and provided prognostic information independent of currently used prognostic factors from the SIN-system, namely tumor size, vascular invasion, and necrosis [43]. Gene expression profiles that correlate with poor outcome have previously been recognized in Ewing sarcoma and leiomyosarcoma $[21,22,44]$, Ren et al. identified a 92-gene signature in 11 leiomyosarcomas that separated high-grade metastatic tumors from low-grade welldifferentiated ones, whereas Lee et al. took a different approach and predicted metastasis in a set of 30 primary leiomyosarcomas and local recurrences using the expression profile of 335 genes that initially distinguished primary leiomyosarcomas from metastases [21,22]. However, none of the reported genes were among our 244 discriminators, which may not only be because they were established in a set of leiomyosarcomas using different approaches whereas our signature was established in a larger mixed series of pleomorphic primary STS, but also due to the difficulties in identifying prognostic signals which are considerably weaker than the diagnostic ones.

An adverse prognostic impact of hypoxia has been demonstrated in several malignancies and tumor oxygenation studies in STS have suggested an association of hypoxia with tumor grade, presence of mitoses and metastatic development [45-48]. A recent study demonstrated that HIF1A expression was an independent prognostic factor in STS [49]. Hypoxic tumors display high rates of glucose uptake and glycolysis regulated by HIF1 that induces expression of glucose transporters like GLUT1 and glycolytic enzymes like ENO1, HK2, LDHB and PGK1[50], which were overexpressed in the metastasizing tumors. CA9 expression, an intrinsic cellular marker for hypoxia, has been suggested to correlate with poor survival in highgrade STS [51], and GLUT1 expression and enhanced glucose metabolism in STS have been linked to proliferative activity and tumor grade [52-55]. Detwiller et al. demonstrated that the expression pattern of a selection of 107 hypoxia-related genes allowed distinction of mixed STS samples from normal tissue, and several of the overexpressed genes therein were among our discriminators [56].

\section{Conclusion}

In summary, diagnostic gene expression profiles were identified for different subtypes with distinct profiles in STS with specific fusion genes or mutations, whereas the diagnostically difficult pleomorphic STS were challenging also with regards to expression profiling. The SS, GIST, myxoid/round-cell liposarcomas, MPNST and fibrosarcomas shared similarities in expression profiles with overrepresentation of developmental genes involved in differentiation and morphogenesis. On the other hand, genes involved in cell-cycle, proliferation, adhesion, motility, protein degradation, homeostasis and immuneresponse seemed to play an important role in the pleomorphic subtypes. The novel genes and pathways identified provide important information about tumor origin and constitute potential therapeutic targets. Our identification of a prognostic profile in the latter group is highly 
promising, and provides information independent of the currently used prognosticators. Moreover, it is intriguing that upregulation of hypoxia-related genes predicts metastatic potential in high-grade, pleomorphic and genetically complex STS and calls for further evaluation of HIF1A and its target genes in STS.

\section{Methods \\ Patients and tumor material}

Tumor samples were obtained from 177 patients operated between 1972 and 2003 at the Lund University Hospital, Lund ( $\mathrm{n}=122)$, the Norwegian Radium Hospital, Oslo ( $\mathrm{n}$ = 47) and the Karolinska Hospital, Stockholm $(n=8)$. Ethical permission for the study was obtained from the Lund University research ethics committee and the Regional Ethics Committee of Southern Norway. The tumor samples consisted of 154 primary tumors, 16 local recurrences and 7 metastases, and the latter samples were included after assuring that neither local recurrences nor metastases formed separate clusters (data not shown). The 177 samples represented 13 subtypes, among which MFH/UPS, leiomyosarcoma and SS together constituted $75 \%$ (Table 1). All tumors were reviewed by the Scandinavian Sarcoma Group (SSG) review board of pathologists and many tumors had in addition been reviewed by one of two reference pathologists (BB \& MÅ), who also belonged to the SSG board of pathologists. The diagnoses were based on the combined information from histopathology, immunohistochemical staining, and cytogenetic and/or molecular genetic analyses. The SS18-SSX gene fusion was confirmed in 24/32 synovial sarcomas (13 with SS18-SSX1, 10 with SS18-SSX2 and 1 with SS18SSX4), and the TLS-CHOP fusion in 2/4 myxoid/roundcell liposarcomas. The 8 MPNST were all derived from patients free of neurofibromatosis. Malignancy grading was based on a IV-tiered scale, and in line with our aim to improve diagnosis of high-grade tumors, $97 \%$ of the tumors were classified as high-grade (grades III and IV). Only a small minority of the patients received preoperative treatment with radiotherapy $(\mathrm{n}=1)$ or chemotherapy $(\mathrm{n}=5)$. The study is aimed at tumors located in the extremities and the trunk wall, but 14/177 (8\%) abdomi$\mathrm{nal} /$ retroperitoneal tumors were included since they contributed with data on rare tumor types and did not cluster separately (data not shown). Besides the 177 patient samples, 17 xenografts (including $6 \mathrm{MFH} / \mathrm{UPS}, 4 \mathrm{MPNST}, 3$ SS, 2 pleomorphic liposarcomas, 1 myxoid/round-cell liposarcoma and 1 GIST) were included, but were not used for the generation of discriminatory gene lists. Analysis of a prognostic expression profile was performed in 89 primary pleomorphic tumors, mostly including MFH/ UPS and leiomyosarcomas. The prognostic system used for clinical decisions included evaluation of necrosis and vascular invasion. Necrosis was classified at histopathological examination either if identified macroscopically or when identified microscopically at careful examination. Necrosis was identified in 66/89 (74\%) tumors in the prognostic subset, thus at a high rate. Vascular invasion also carefully examined for prognostic purposes was identified in $17 / 89(19 \%)$ of the tumors (Table 1). All 89 patients had undergone primary surgery without preoperative radio- or chemotherapy and only 9 patients were treated with postoperative chemotherapy. Metastasis developed in $39(44 \%)$ patients after median 9 (range 0$65)$ months and the mean follow-up for the survivors was 7 (range 1-16) years.

\section{RNA extraction and CDNA microarray analysis}

RNA extractions from 47 tumors and the 17 xenografts were carried out at the Norwegian Radium Hospital, whereas the remaining 130 samples were extracted at the Lund University Hospital, and all 194 samples were labeled and hybridized in Lund. The cDNA microarray slides used were produced at the Swegene DNA Microarray Resource Center, Department of Oncology, Lund University and contained 27649 spots with sequence-verified IMAGE clones from the Research Genetics IMAGE clone library. The clone information was linked to gene names using build 180 of the Unigene database [57] and 16000 unique Unigene clusters were represented on the array. The RNA extraction, cDNA synthesis, labeling, hybridization and subsequent image and data processing were carried out as previously described [58]. Background correction, filtering, transformations and analyses were performed using a local installation of the web-based BioArray Software Environment (BASE) [59,60]. A preliminary filtering step eliminated all spots of poor quality like those flagged 'not found' or 'bad' in GenePix ${ }^{\mathrm{TM}}$ Pro 4.1.1.4 version (Axon instruments Inc., Foster City, CA), spots with diameter lesser than or equal to $60 \mu \mathrm{m}$, spots with more than $10 \%$ pixel saturation and signal-to-noise ratio less than 1.5 in either channel. The background corrected intensity values were then normalized using the pin-based LOWESS method to compensate for dye bias and local background effects [61]. Here, intensity dependent adjustments (LOWESS fits) were performed within groups of 16 blocks to correct for spatial bias. Multiple print batches of slides were used, with 41 samples hybridized in replicates on different batches. All repeats clustered next to the first sample run irrespective of the differences in print batch (data not shown), hence replicate assays were merged in a weighted fashion, as previously described [58]. Within each slide, expression values for spots associated to the same gene symbol were merged in a similar weighted fashion. A student's t-test identified $\sim 2500$ genes $(P=$ $0.05)$ that differed in expression between samples extracted in Norway and Sweden and 1800 genes $(P=$ $0.05)$ that differed between tumors and xenografts suggesting the presence of technical and biological bias within the data set. In order to eliminate the technical bias 
introduced by the RNA extractions carried out at different laboratories, centering was applied independently to the 64 (tumors and xenografts) Norwegian and 130 Swedish samples. The xenograft samples, wherever used in the analysis, were centered separately a second time to compensate for the inherent biological differences that exist between tumors and xenografts. Following independent centering of the mentioned sample groups, the student's t-test failed to identify significant genes that distinguished the groups confirming that very little, if any, of the bias remained. Moreover, in later steps no apparent clustering was observed based on RNA extraction or depending on whether the sample was from a tumor or xenograft. The data were then transformed using an error model, as previously described, to reduce the importance of poor-quality spots in later analysis steps [58]. Filters for variation and presence of expression across hybridizations were set to reject all spots with a standard deviation of modified expression value smaller than 0.2 and a presence in less than $70 \%$ of the samples. Unsupervised agglomerative hierarchical clustering was performed with the help of the $\mathrm{TMeV}$ application from the $\mathrm{TM}_{4}$ microarray software suite [62], using the average-linkage method and the Pearson correlation distance metric [63].

Golub-score analyses, named after the widely referenced paper by Golub et al. [64], and random permutations were performed as previously described [58] on 177 and 142 (excluding SS and GIST) tumor samples in order to generate discriminatory gene lists for the different subtypes. The SS and GIST, which revealed distinct expression patterns, were excluded in order to identify the more subtle differences in genetic profiles of the remaining STS subtypes. Approximately 6000 genes were ranked on their Golubscores - a high score for a gene implicating minor variation in expression within the subtype but large variation between the subtypes, in turn implicating high discriminating power. 1000 random permutations were performed to assess the discriminating power of the scores and to establish FDR. Furthermore, the 19 liposarcoma samples (16 tumors and 3 xenografts) were analyzed independently to identify a genetic signature distinguishing the myxoid/round-cell liposarcomas from the dedifferentiated/pleomorphic liposarcomas.

Golub-score analysis was also used to identify a metastatic signature within a subset of 89 primary, mainly highgrade, pleomorphic tumors. To obtain a more robust list of prognostic discriminators, a consensus gene list was created. The 89 samples, 39 of which metastasized, were randomly split into two halves preserving the ratio of metastasizing samples and each half was used to create two Golub-score ranked gene lists. The above step was iterated 100 times to obtain 200 gene lists in total, from which a consensus gene list was established by ordering genes according to median rank. The top 244 genes (median rank $<700$ ) were used to cluster the samples in $\mathrm{TMeV}$. Thereafter, leave-one-out cross-validation using the SVM option in TMeV was performed on the 89 samples based on all 5500 genes that passed the above-mentioned filter criteria in order to obtain an unbiased classification that was later used in the univariate and multivariate analyses.

The discriminatory gene lists were further analyzed using the EASE software [65] to functionally classify the genes and facilitate biological interpretations [66]. The top ranked genes were classified into groups within the categorical systems of the Gene Ontology (GO) Consortium (GO Biological Process and GO Molecular Function), the KEGG pathway, biochemical process, cellular role and chromosomal regions. The EASE analyses in SS and myxoid/round-cell liposarcomas employed the top 4000 and 1000 genes (with $11 \%$ FDR) respectively. Gene lists with less stringent cut-offs were used for the GIST (top 1500 with $25 \%$ FDR), MFH/UPS (top 500 with $16 \%$ FDR), leiomyosarcomas (top 500 with $26 \%$ FDR) and MPNST (top 500 with 27\% FDR), which allowed more genes into the gene lists making it possible to identify functional correlations between the discriminatory genes and similarities in expression profiles between the different subtypes. Focusing on upregulated pathways and functional groups rather than on individual genes reduces the risk of signifying biologically irrelevant genes, especially in gene lists with high FDR. All functional groups mentioned had an EASE score $<0.05$.

\section{Statistical analyses}

The $\chi^{2}$ test for association, the Mann-Whitney's U test, and the Kruskal-Wallis test were used to assess associations of tumor size (as a continuous variable), necrosis (present $v$ s. absent), vascular invasion (present $v s$. absent), and the SVM cross-validated classification with the development of metastasis. Metastasis-free survival curves were constructed by the Kaplan-Meier method and compared by the log-rank test. Univariate and multivariate Cox-regression analyses were performed to estimate HRs and to assess the independence of the cross-validated classification from the above-mentioned prognostic factors. Proportional hazards assumptions were checked using Schoenfeld's test [67]. Areas under ROC curves were compared using an algorithm suggested by DeLong et al. [68]. A two-tailed $P$-value of less than 0.05 was considered significant for all tests. Stata 9.2 was used for the statistical analyses (Stata Corporation, 2003, College Station, TX).

\section{Abbreviations}

Soft tissue sarcoma: STS; Malignant fibrous histiocytoma: MFH; Undifferentiated pleomorphic sarcoma: UPS; Synovial sarcoma: SS; Malignant peripheral nerve sheath 
tumor: MPNST; Gastrointestinal stromal tumors: GIST; Not otherwise specified: NOS; False-discovery rates: FDR; Hedgehog: Hh; Retinoic acid receptor: RAR; EASE: Expression Analysis Systematic Explorer; SWI/SNF related matrix associated actin dependent regulator of chromatin: SMARC; Support vector machine: SVM; Receiver operating characteristic: ROC; Hazard Ratio: HR; Scandinavian Sarcoma Group: SSG; BioArray Software Environment: BASE; Gene Ontology: GO

\section{Authors' contributions}

PF drafted the manuscript and carried out RNA extractions, hybridizations and data analyses. HMN performed extractions and hybridizations of the Norwegian samples and participated in the data analyses. CM assisted with clinical annotations of the Norwegian samples. PE designed the BASE plug-ins and assisted with the computational analyses. JF, JMB and AI performed RNA extractions and hybridizations. $\mathrm{BB}$ and $\mathrm{MA}$ were the pathologists who reviewed the tumor samples. POB performed the statistical analyses. AR participated in the design of the study and clinically annotated the Swedish samples. OM and MN conceived of the study, and participated in its design and coordination. All authors read and approved the final manuscript.

\section{Additional material}

\section{Additional file 1}

Unsupervised cluster analysis of the 194 STS samples including 17 xenografts. Figure A shows the unsupervised cluster analysis of the 194 STS samples where 2/3 synovial sarcoma xenografts and the single GIST and myxoid/round-cell liposarcoma xenografts clustered with their respective tumor histotypes, whereas all 6 MFH xenografts were part of the pleomorphic STS subcluster (the xenografts are indicated by red arrows).

Figure B shows the same unsupervised cluster as above, this time showing the 3 xenografts derived from tumors included in the study (red arrows) that clustered next to their respective patient samples (blue arrows). Click here for file

[http://www.biomedcentral.com/content/supplementary/14712164-8-73-S1.jpeg]

\section{Additional file 2}

Independent analysis of the 19 liposarcoma samples including 16 patient samples and 3 xenografts. Figure A shows unsupervised cluster analysis of the 19 liposarcoma samples. The plot in figure $B$ shows FDR within the Golub-score ranked genes distinguishing the myxoid/round-cell liposarcomas from the dedifferentiated/pleomorphic liposarcomas. The number of ranked genes is plotted along the $x$-axis and FDR along the $y$-axis. Figure $C$ shows supervised clustering of the 19 liposarcoma samples based on the top 1000 genes discriminating the myxoid/round-cell liposarcomas from the dedifferentiated/pleomorphic liposarcomas.

Click here for file

[http://www.biomedcentral.com/content/supplementary/14712164-8-73-S2.jpeg]

\section{Additional file 3}

FDR plots for the diagnostic signatures. FDR plots for the diagnostic signatures with the number of ranked genes plotted along the $x$-axis and FDR along the $\gamma$-axis. Random permutation tests with 1000 permutations were performed to assess the discriminating power or robustness of the Golubscore ranked genes. For each rank, the average number of genes in a permutation list above that rank was divided by the number of genes in the true list to get the FDR.

Click here for file

[http://www.biomedcentral.com/content/supplementary/14712164-8-73-S3.jpeg]

\section{Additional file 4}

Numbers and percentages of false positives among the top ranked genes. A table showing the numbers and percentages of false positives among the Golub-score ranked genes for the different discriminatory gene lists. Click here for file

[http://www.biomedcentral.com/content/supplementary/14712164-8-73-S4.xls]

\section{Additional file 5}

Supervised clustering based on the SS signature. Supervised clustering of 177 STS samples based on the top 4000 synovial sarcoma discriminating genes.

Click here for file

[http://www.biomedcentral.com/content/supplementary/1471-

2164-8-73-S5.jpeg]

\section{Additional file 6}

Top 4000 genes discriminating the synovial sarcomas from the remaining STS subtypes. The SS discriminators.

Click here for file

[http://www.biomedcentral.com/content/supplementary/1471-

2164-8-73-S6.xls]

\section{Additional file 7}

Supervised clustering based on the GIST signature. Supervised clustering of 177 STS samples based on the top 1500 GIST discriminating genes. Click here for file

[http://www.biomedcentral.com/content/supplementary/14712164-8-73-S7.jpeg]

\section{Additional file 8}

Top 1500 genes discriminating the GIST from the remaining STS subtypes. The GIST discriminators.

Click here for file

[http://www.biomedcentral.com/content/supplementary/1471-

2164-8-73-S8.xls]

\section{Additional file 9}

Supervised clustering based on the myxoid/round-cell liposarcoma signature. Supervised clustering of 142 STS samples based on the top 1000 myxoid/round-cell liposarcoma discriminating genes.

Click here for file

[http://www.biomedcentral.com/content/supplementary/14712164-8-73-S9.jpeg] 


\section{Additional file 10}

Top 1000 genes discriminating the myxoid/round-cell liposarcomas from the remaining STS subtypes. The myxoid/round-cell liposarcoma discriminators.

Click here for file

[http://www.biomedcentral.com/content/supplementary/1471-

2164-8-73-S10.xls]

\section{Additional file 11}

Supervised clustering based on the MPNST signature. Supervised clustering of 142 STS samples based on the top 500 MPNST discriminating genes.

Click here for file

[http://www.biomedcentral.com/content/supplementary/1471-

2164-8-73-S11.jpeg]

\section{Additional file 12}

Top 500 genes discriminating the MPNST from the remaining STS subtypes. The MPNST discriminators.

Click here for file

[http://www.biomedcentral.com/content/supplementary/1471-

2164-8-73-S12.xls]

\section{Additional file 13}

Supervised clustering based on the leiomyosarcoma signature. Supervised clustering of 142 STS samples based on the top 500 leiomyosarcoma discriminating genes.

Click here for file

[http://www.biomedcentral.com/content/supplementary/1471-

2164-8-73-S13.jpeg]

\section{Additional file 14}

Top 500 genes discriminating the leiomyosarcomas from the remaining STS subtypes. The leiomyosarcoma discriminators.

Click here for file

[http://www.biomedcentral.com/content/supplementary/14712164-8-73-S14.xls]

\section{Additional file 15}

Supervised clustering based on the MFH/UPS signature. Supervised clustering of 142 STS samples based on the top 500 MFH/UPS discriminating genes.

Click here for file

[http://www.biomedcentral.com/content/supplementary/1471-

2164-8-73-S15.jpeg]

\section{Additional file 16}

Top 500 genes discriminating the MFH/UPS from the remaining STS subtypes. The MFH/UPS discriminators.

Click here for file

[http://www.biomedcentral.com/content/supplementary/14712164-8-73-S16.xls]

\section{Additional file 17}

Supervised clustering based on the dedifferentiated/pleomorphic liposarcoma signature. Supervised clustering of 142 STS samples based on the top 150 dedifferentiated/pleomorphic liposarcoma discriminating genes showing 5/12 dedifferentiated/pleomorphic liposarcomas clustered tightly with $2 \mathrm{MFH/UPS,} 2$ leiomyosarcomas and 1 fibrosarcoma, all of which possess the CDK4-MDM2 amplification.

Click here for file

[http://www.biomedcentral.com/content/supplementary/14712164-8-73-S17.jpeg]

\section{Additional file 18}

Top 150 genes discriminating the dedifferentiated/pleomorphic liposarcomas from the remaining STS subtypes. The dedifferentiated/pleomorphic liposarcoma discriminators.

Click here for file

[http://www.biomedcentral.com/content/supplementary/1471-

2164-8-73-S18.xls]

\section{Additional file 19}

Supervised clustering based on the fibrosarcoma signature. Supervised clustering of 142 STS samples based on the top 100 (44\% FDR) and top $200(50 \% \mathrm{FDR})$ fibrosarcoma discriminating genes.

Click here for file

[http://www.biomedcentral.com/content/supplementary/14712164-8-73-S19.jpeg]

\section{Additional file 20}

Top 200 genes discriminating the fibrosarcomas from the remaining STS subtypes. The fibrosarcoma discriminators.

Click here for file

[http://www.biomedcentral.com/content/supplementary/1471-

2164-8-73-S20.xls]

\section{Additional file 21}

Top 1000 genes discriminating the myxoid/round-cell liposarcomas from the dedifferentiated/pleomorphic liposarcomas. The genes distinguishing the myxoid/round-cell liposarcomas from the dedifferentiated/pleomorphic liposarcomas in an independent analysis of 19 liposarcoma samples including 3 xenografts.

Click here for file

[http://www.biomedcentral.com/content/supplementary/1471-

2164-8-73-S21.xls]

\section{Additional file 22}

Top 244 genes sorted on median rank discriminating the tumors that developed metastasis from the ones that were metastasis-free. The metastasis signature established in 89 high-grade pleomorphic primary tumors. Click here for file

[http://www.biomedcentral.com/content/supplementary/14712164-8-73-S22.xls]

\section{Acknowledgements}

We would like to thank the orthopedic surgeons at the University Hospitals in Oslo, Stockholm, and Lund for preserving tumor tissue and the pathologists within the Scandinavian Sarcoma Group for histopathological review. This study was supported by grants from the Swedish Cancer Society, the Swedish Research Council, the Nilsson Cancer Fund, the Kamprad Research Fund, the K. and A. Wallenberg Foundation via the SWEGENE program, the Swedish Foundation for Strategic Research through the Lund 
Center for Stem Cell Biology and Cell Therapy, the Swedish Children's Cancer Fund, the Research Funds at Lund University Hospital, the Norwegian Cancer Society, and the Norwegian Health and Rehabilitation Fund.

\section{References}

I. Fletcher CDM, Unni KK, Mertens F, editors: WHO classification of tumours; pathology and genetics: tumours of soft tissue and bone. Lyon, France: IARC Press; 2002.

2. Helman LJ, Meltzer P: Mechanisms of sarcoma development. Nat Rev Cancer 2003, 3(9):685-694.

3. Borden EC, Baker LH, Bell RS, Bramwell V, Demetri GD, Eisenberg $B L$, Fletcher CD, Fletcher JA, Ladanyi M, Meltzer P, et al:: Soft tissue sarcomas of adults: state of the translational science. Clin Cancer Res 2003, 9(6): 194I-1956

4. Allander SV, Illei PB, Chen Y, Antonescu CR, Bittner M, Ladanyi M, Meltzer PS: Expression profiling of synovial sarcoma by cDNA microarrays: association of ERBB2, IGFBP2, and ELF3 with epithelial differentiation. Am J Pathol 2002, I6 I(5): 1587-1595.

5. Allander SV, Nupponen NN, Ringner M, Hostetter G, Maher GW, Goldberger N, Chen Y, Carpten J, Elkahloun AG, Meltzer PS: Gastrointestinal stromal tumors with KIT mutations exhibit a remarkably homogeneous gene expression profile. Cancer Res 200I, 6 I (24):8624-8628.

6. Baer C, Nees M, Breit S, Selle B, Kulozik AE, Schaefer KL, Braun Y, Wai D, Poremba C: Profiling and functional annotation of mRNA gene expression in pediatric rhabdomyosarcoma and Ewing's sarcoma. Int J Cancer 2004, I l 0(5):687-694.

7. Baird K, Davis S, Antonescu CR, Harper UL, Walker RL, Chen Y, Glatfelter AA, Duray PH, Meltzer PS: Gene expression profiling of human sarcomas: insights into sarcoma biology. Cancer Res 2005, 65(20):9226-9235.

8. Linn SC, West RB, Pollack JR, Zhu S, Hernandez-Boussard T, Nielsen TO, Rubin BP, Patel R, Goldblum JR, Siegmund D, et al:: Gene expression patterns and gene copy number changes in dermatofibrosarcoma protuberans. Am J Pathol 2003, 163(6):2383-2395.

9. Nagayama S, Katagiri T, Tsunoda T, Hosaka T, Nakashima Y, Araki N, Kusuzaki K, Nakayama T, Tsuboyama T, Nakamura T, et al: Genome-wide analysis of gene expression in synovial sarcomas using a cDNA microarray. Cancer Res 2002, 62(20):5859-5866.

10. Segal NH, Pavlidis P, Antonescu CR, Maki RG, Noble WS, DeSantis D, Woodruff JM, Lewis J], Brennan MF, Houghton AN, et al: Classification and subtype prediction of adult soft tissue sarcoma by functional genomics. Am J Pathol 2003, I 63(2):69|-700.

II. Segal NH, Pavlidis P, Noble WS, Antonescu CR, Viale A, Wesley UV, Busam K, Gallardo H, DeSantis D, Brennan MF, et al.: Classification of clear-cell sarcoma as a subtype of melanoma by genomic profiling. J Clin Oncol 2003, 2 I(9): 1775-I78I.

12. Skubitz KM, Skubitz AP: Characterization of sarcomas by means of gene expression. J Lab Clin Med 2004, I44(2):78-9|.

13. Wachtel M, Dettling M, Koscielniak E, Stegmaier S, Treuner J, SimonKlingenstein K, Buhlmann P, Niggli FK, Schafer BW: Gene expression signatures identify rhabdomyosarcoma subtypes and detect a novel $t(2 ; 2)(q 35 ; p 23)$ translocation fusing PAX3 to NCOAI. Cancer Res 2004, 64(16):5539-5545.

14. West RB, van de Rijn M: The role of microarray technologies in the study of soft tissue tumours. Histopathology 2006, 48(I):22-31.

15. Fukukawa C, Nakamura Y, Katagiri T: Molecular target therapy for synovial sarcoma. Future oncology (London, England) 2005, I(6):805-8I2

16. Ishibe T, Nakayama T, Okamoto T, Aoyama T, Nishijo K, Shibata KR, Shima Y, Nagayama S, Katagiri T, Nakamura Y, et al.: Disruption of fibroblast growth factor signal pathway inhibits the growth of synovial sarcomas: potential application of signal inhibitors to molecular target therapy. Clin Cancer Res 2005, I I(7):2702-27I2.

17. Lubieniecka JM, Nielsen TO: cDNA microarray-based translational research in soft tissue sarcoma. Journal of surgical oncology 2005, 92(4):267-27I.

18. Nagayama S, Fukukawa C, Katagiri T, Okamoto T, Aoyama T, Oyaizu $\mathrm{N}$, Imamura M, Toguchida J, Nakamura Y: Therapeutic potential of antibodies against FZD 10, a cell-surface protein, for synovial sarcomas. Oncogene 2005, 24(4I):620I-62I2.
19. Nielsen TO, West RB, Linn SC, Alter O, Knowling MA, O'Connell JX, Zhu S, Fero M, Sherlock G, Pollack JR, et al.: Molecular characterisation of soft tissue tumours: a gene expression study. Lancet 2002, 359(93 | 4): | 30|- | 307

20. Lee YF, John M, Edwards S, Clark J, Flohr P, Maillard K, Edema M, Baker L, Mangham DC, Grimer R, et al.: Molecular classification of synovial sarcomas, leiomyosarcomas and malignant fibrous histiocytomas by gene expression profiling. Br J Cancer 2003, 88(4):5I0-5I5.

21. Ren B, Yu YP, Jing L, Liu L, Michalopoulos GK, Luo JH, Rao UN: Gene expression analysis of human soft tissue leiomyosarcomas. Hum Pathol 2003, 34(6):549-558.

22. Lee YF, John M, Falconer A, Edwards S, Clark J, Flohr P, Roe T, Wang R, Shipley J, Grimer RJ, et al.: A gene expression signature associated with metastatic outcome in human leiomyosarcomas. Cancer Res 2004, 64(20):720I-7204.

23. Berner JM, Forus A, Elkahloun A, Meltzer PS, Fodstad O, Myklebost $O$ : Separate amplified regions encompassing CDK4 and MDM2 in human sarcomas. Genes Chromosomes Cancer 1996, I 7(4):254-259.

24. Pisters PW, Leung DH, Woodruff J, Shi W, Brennan MF: Analysis of prognostic factors in I,04I patients with localized soft tissue sarcomas of the extremities. I Clin Oncol 1996, 14(5): 1679-1689.

25. Koea JB, Leung D, Lewis JJ, Brennan MF: Histopathologic type: an independent prognostic factor in primary soft tissue sarcoma of the extremity? Ann Surg Oncol 2003, 1 0(4):432-440.

26. Giaccia AJ, Simon MC, Johnson R: The biology of hypoxia: the role of oxygen sensing in development, normal function, and disease. Genes Dev 2004, 18(18):2183-2194.

27. Shimoji T, Kanda H, Kitagawa T, Kadota K, Asai R, Takahashi K, Kawaguchi N, Matsumoto S, Hayashizaki Y, Okazaki Y, et al:: Clinicomolecular study of dedifferentiation in well-differentiated liposarcoma. Biochem Biophys Res Commun 2004, 3 |4(4): I |33-I| 40

28. Suehara Y, Kondo T, Fujii K, Hasegawa T, Kawai A, Seki K, Beppu Y, Nishimura T, Kurosawa H, Hirohashi S: Proteomic signatures corresponding to histological classification and grading of soft-tissue sarcomas. Proteomics 2006

29. Crew AJ, Clark J, Fisher C, Gill S, Grimer R, Chand A, Shipley J, Gusterson BA, Cooper CS: Fusion of SYT to two genes, SSXI and SSX2, encoding proteins with homology to the Kruppelassociated box in human synovial sarcoma. Embo J 1995, I 4( I 0):2333-2340

30. Skytting B, Nilsson G, Brodin B, Xie Y, Lundeberg J, Uhlen M, Larsson O: A novel fusion gene, SYT-SSX4, in synovial sarcoma. J Natl Cancer Inst 1999, 9 I(I I):974-975.

3I. Kato H, Tjernberg A, Zhang W, Krutchinsky AN, An W, Takeuchi T, Ohtsuki Y, Sugano S, de Bruijn DR, Chait BT, et al.: SYT associates with human SNF/SWI complexes and the C-terminal region of its fusion partner SSXI targets histones. J Biol Chem 2002, 277(7):5498-5505.

32. Perani M, Ingram CJ, Cooper CS, Garrett MD, Goodwin GH: Conserved SNH domain of the proto-oncoprotein SYT interacts with components of the human chromatin remodelling complexes, while the QPGY repeat domain forms homo-oligomers. Oncogene 2003, 22(50):8|56-8|67.

33. Thaete C, Brett D, Monaghan P, Whitehouse S, Rennie G, Rayner E, Cooper CS, Goodwin G: Functional domains of the SYT and SYT-SSX synovial sarcoma translocation proteins and colocalization with the SNF protein BRM in the nucleus. Hum Mol Genet 1999, 8(4):585-591.

34. Smith TA, Machen SK, Fisher C, Goldblum JR: Usefulness of cytokeratin subsets for distinguishing monophasic synovial sarcoma from malignant peripheral nerve sheath tumor. $\mathrm{Am} J$ Clin Pathol 1999, I I 2(5):64 I-648.

35. Hirota $S$, Isozaki $K$, Moriyama $Y$, Hashimoto $K$, Nishida T, Ishiguro $S$, Kawano K, Hanada M, Kurata A, Takeda M, et al: Gain-of-function mutations of c-kit in human gastrointestinal stromal tumors. Science 1998, 279(5350):577-580.

36. Sircar K, Hewlett BR, Huizinga JD, Chorneyko K, Berezin I, Riddell $\mathrm{RH}$ : Interstitial cells of Cajal as precursors of gastrointestinal stromal tumors. Am J Surg Pathol 1999, 23(4):377-389.

37. Crozat A, Aman P, Mandahl N, Ron D: Fusion of CHOP to a novel RNA-binding protein in human myxoid liposarcoma. Nature 1993, 363(6430):640-644. 
38. Demetri GD, Fletcher CD, Mueller E, Sarraf P, Naujoks R, Campbell $\mathrm{N}$, Spiegelman BM, Singer S: Induction of solid tumor differentiation by the peroxisome proliferator-activated receptorgamma ligand troglitazone in patients with liposarcoma. Proc Natl Acad Sci USA I 999, 96(7):395 I-3956.

39. Tontonoz P, Singer S, Forman BM, Sarraf P, Fletcher JA, Fletcher CD, Brun RP, Mueller E, Altiok S, Oppenheim H, et al:: Terminal differentiation of human liposarcoma cells induced by ligands for peroxisome proliferator-activated receptor gamma and the retinoid X receptor. Proc Natl Acad Sci USA 1997, 94(I):237-24I.

40. Pedeutour F, Forus A, Coindre JM, Berner JM, Nicolo G, Michiels JF, Terrier P, Ranchere-Vince D, Collin F, Myklebost O, et al: Structure of the supernumerary ring and giant rod chromosomes in adipose tissue tumors. Genes Chromosomes Cancer 1999 , 24(I):30-4I.

4I. Shimada S, Ishizawa T, Ishizawa K, Matsumura T, Hasegawa T, Hirose T: The value of MDM2 and CDK4 amplification levels using real-time polymerase chain reaction for the differential diagnosis of liposarcomas and their histologic mimickers. Hum Pathol 2006, 37(9): I I 23-I I 29.

42. Skubitz KM, Cheng EY, Clohisy DR, Thompson RC, Skubitz AP: Dif ferential gene expression in liposarcoma, lipoma, and adipose tissue. Cancer Invest 2005, 23(2): 105-1 I8.

43. Gustafson P, Akerman M, Alvegard TA, Coindre JM, Fletcher CD, Rydholm A, Willen H: Prognostic information in soft tissue sarcoma using tumour size, vascular invasion and microscopic tumour necrosis-the SIN-system. Eur J Cancer 2003, 39(I I): I568-I576.

44. Ohali A, Avigad S, Zaizov R, Ophir R, Horn-Saban S, Cohen IJ, Meller I, Kollender Y, Issakov J, Yaniv I: Prediction of high risk Ewing's sarcoma by gene expression profiling. Oncogene 2004, 23(55):8997-9006.

45. Brizel DM, Scully SP, Harrelson JM, Layfield LJ, Bean JM, Prosnitz LR, Dewhirst MW: Tumor oxygenation predicts for the likelihood of distant metastases in human soft tissue sarcoma. Cance Res 1996, 56(5):941-943.

46. Brizel DM, Sibley GS, Prosnitz LR, Scher RL, Dewhirst MW: Tumor hypoxia adversely affects the prognosis of carcinoma of the head and neck. Int J Radiat Oncol Biol Phys 1997, 38(2):285-289.

47. Evans SM, Fraker D, Hahn SM, Gleason K, Jenkins WT, Jenkins K, Hwang WT, Zhang P, Mick R, Koch C): EF5 binding and clinical outcome in human soft tissue sarcomas. Int I Radiat Oncol Biol Phys 2006, 64(3):922-927.

48. Nordsmark M, Alsner J, Keller J, Nielsen OS, Jensen OM, Horsman $M R$, Overgaard J: Hypoxia in human soft tissue sarcomas: adverse impact on survival and no association with p53 mutations. $\mathrm{Br} /$ Cancer 200I, 84(8): 1070-1075.

49. Shintani K, Matsumine A, Kusuzaki K, Matsubara T, Satonaka $H$ Wakabayashi T, Hoki Y, Uchida A: Expression of hypoxia-inducible factor (HIF)- I alpha as a biomarker of outcome in soft-tissue sarcomas. Virchows Arch 2006, 449(6):673-68I.

50. Dang CV, Semenza GL: Oncogenic alterations of metabolism. Trends Biochem Sci 1999, 24(2):68-72.

5I. Maseide K, Kandel RA, Bell RS, Catton CN, O'Sullivan B, Wunder JS, Pintilie M, Hedley D, Hill RP: Carbonic anhydrase IX as a marker for poor prognosis in soft tissue sarcoma. Clin Cancer Res 2004, I 0( I 3):4464-447I.

52. Bastiaannet E, Groen H, Jager PL, Cobben DC, van der Graaf WT, Vaalburg W, Hoekstra HJ: The value of FDG-PET in the detection, grading and response to therapy of soft tissue and bone sarcomas; a systematic review and meta-analysis. Cancer Treat Rev 2004, 30(I):83-101.

53. Folpe AL, Lyles RH, Sprouse JT, Conrad EU, Eary JF 3rd: (F-I8) fluorodeoxyglucose positron emission tomography as a predictor of pathologic grade and other prognostic variables in bone and soft tissue sarcoma. Clin Cancer Res 2000 6(4): $1279-1287$

54. Nordsmark M, Hoyer M, Keller J, Nielsen OS, Jensen OM, Overgaard ]: The relationship between tumor oxygenation and cell proliferation in human soft tissue sarcomas. Int I Radiat Oncol Biol Phys 1996, 35(4):701-708.

55. Tateishi U, Yamaguchi U, Seki K, Terauchi T, Arai Y, Hasegawa T: Glut-I expression and enhanced glucose metabolism are associated with tumour grade in bone and soft tissue sarcomas: a prospective evaluation by $[(18) F]$ fluorodeoxyglucose positron emission tomography. Eur J Nucl Med Mol Imaging 2006, 33(6):683-69l.

56. Detwiller KY, Fernando NT, Segal NH, Ryeom SW, D'Amore PA, Yoon SS: Analysis of hypoxia-related gene expression in sarcomas and effect of hypoxia on RNA interference of vascular endothelial cell growth factor A. Cancer Res 2005, 65(I3):588|-5889.

57. The UniGene database [http://www.ncbi.nlm.nih.gov/UniGene]

58. Fernebro J, Francis P, Eden P, Borg A, Panagopoulos I, Mertens F, Vallon-Christersson J, Akerman M, Rydholm A, Bauer HC, et al.: Gene expression profiles relate to SSI 8/SSX fusion type in synovial sarcoma. Int / Cancer 2006, I I 8(5): I | 65-72

59. The BioArray Software Environment (BASE) website [http:/ /base.onk.lu.se/int/]

60. Saal LH, Troein C, Vallon-Christersson J, Gruvberger S, Borg A Peterson C: BioArray Software Environment (BASE): a platform for comprehensive management and analysis of microarray data. Genome Biol 2002, 3(8):SOFTWARE0003.

61. Yang YH, Dudoit S, Luu P, Lin DM, Peng V, Ngai J, Speed TP: Normalization for cDNA microarray data: a robust composite method addressing single and multiple slide systematic variation. Nucleic Acids Res 2002, 30(4):el 5.

62. TMeV version $\mathbf{4 . 0}$ is freely available at the TM4 microarray software suite website [http://www.tm4.org/mev.html]

63. Saeed Al, Sharov V, White J, Li J, Liang W, Bhagabati N, Braisted J, Klapa M, Currier T, Thiagarajan M, et al.: TM4: a free, open-source system for microarray data management and analysis. Biotechniques 2003, 34(2):374-378.

64. Golub TR, Slonim DK, Tamayo P, Huard C, Gaasenbeek M, Mesirov JP, Coller H, Loh ML, Downing JR, Caligiuri MA, et al.: Molecular classification of cancer: class discovery and class prediction by gene expression monitoring. Science 1999. 286(5439):53|-537.

65. The EASE software is freely available at the DAVID Bioinformatics Resources 2007 website of the National Institute of Allergy and Infectious Diseases (NIAID), NIH [http:// david.abcc.ncifcrf.gov/]

66. Hosack DA, Dennis G Jr, Sherman BT, Lane HC, Lempicki RA: Identifying biological themes within lists of genes with EASE. Genome Biol 2003, 4( I 0):R70.

67. Schoenfeld DA, Richter JR: Nomograms for calculating the number of patients needed for a clinical trial with survival as an endpoint. Biometrics 1982, 38(I): |63-170.

68. DeLong ER, DeLong DM, Clarke-Pearson DL: Comparing the areas under two or more correlated receiver operating characteristic curves: a nonparametric approach. Biometrics 1988, 44(3):837-845

Publish with Bio Med Central and every scientist can read your work free of charge

"BioMed Central will be the most significant development for disseminating the results of biomedical research in our lifetime. "

Sir Paul Nurse, Cancer Research UK

Your research papers will be:

- available free of charge to the entire biomedical community

- peer reviewed and published immediately upon acceptance

- cited in PubMed and archived on PubMed Central

- yours - you keep the copyright
BioMedcentral 